\title{
Banka Çalışanlarının Kariyer Bağlılık Düzeylerinin Öznel Kariyer Başarıları Üzerindeki Etkisi \\ (The Effect of Career Commitment of Bank Employees on Subjective Career Success)
}

\section{Zümrüt Hatun DEMİREL iDa}

aAnkara Yıldırım Beyazıt Üniversitesi, Şereflikoçhisar Uygulamalı Bilimler Fakültesi, Şereflikoçhisar, Ankara, Türkiye. zumruthatun@gmail.com

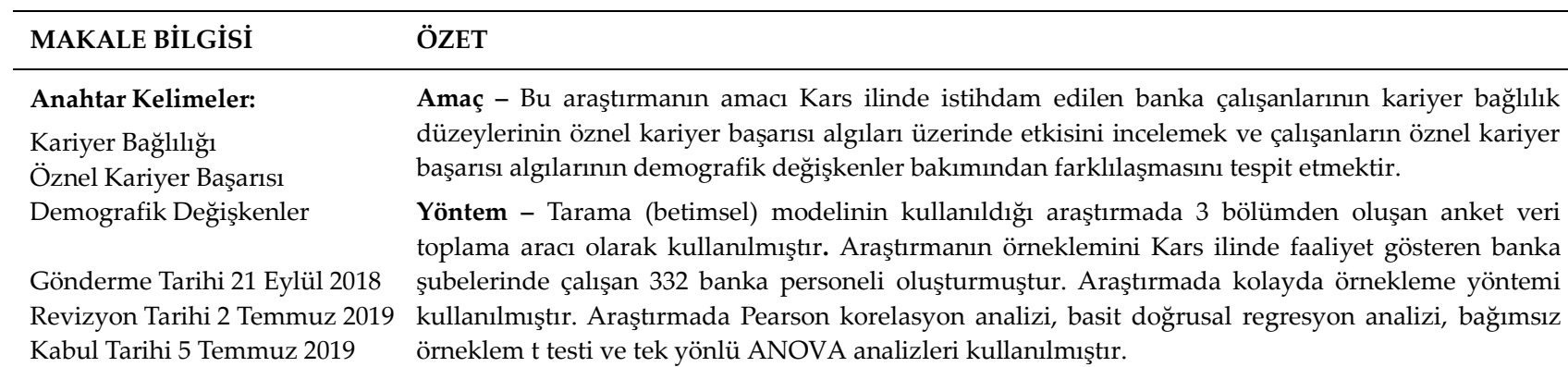

Bulgular - Analizler sonucunda banka çalışanlarının kariyer bağlılık düzeyleri ile öznel kariyer başarı algıları arasında istatistiksel açıdan anlamlı, zayıf ve pozitif yönlü bir ilişki tespit edilmiştir.

Makale Kategorisi: Ayrıca araştırma sonucuna göre banka çalışanlarının kariyer bağlılık düzeyleri öznel kariyer başarısı algılarını pozitif yönde etkilemektedir. Bununla birlikte yapılan analizler kapsamında öznel kariyer başarısının cinsiyet, yaş, çalıştıkları departman, sektörde çalışma süresi gibi demografik değişkenler bakımından farklılaştı̆̆ı, medeni durum ve eğitim düzeyi gibi demografik değişkenler bakımından ise farklılaşmadığı sonucuna ulaşılmıştır.

Tartışma - Çalışanların çalışma hayatlarında başlıca hedeflerinden biri kariyerlerinde başarılı olmaktır. Kariyer bağlılığı kariyer başarısında etkili olan bir değişkendir. Yapılan çalışmalar kariyerlerine bağlı olan çalışanların kariyerlerinde daha başarılı olma eğiliminde olduklarını göstermektedir. Gelecekte yapılması düşünülen araştırmaların daha kapsamlı yapılması alan yazına daha fazla katkı sağlayabilir. Bunun dışında araştırmacılara özellikle farklı sektörlerde veya daha büyük bir örneklem hacmi ile bankacılık sektöründe kariyer başarısının belirleyicilerinin incelenmesi önerilmektedir. Bu belirleyicilerin tespit edilmesi ile örgütler hem çalışanlarının hem de örgütün verimliliğini artırıcı politikalar üretebilecekleri düşünülmektedir.

\begin{tabular}{l}
\hline ARTICLE INFO \\
\hline Keywords: \\
Career Commitment \\
Subjective Career Success \\
Demographic Variables
\end{tabular}

\section{ABSTRACT}

Received 21 September 2018

Revised 2 July 2019

Accepted 5 July 2019

Article Classification: Research Article
Purpose - The aim of this study is to examine the effect of career commitment levels of the bank employees employed in Kars on their subjective career success perceptions and to determine the differences in their perceptions of subjective career success in terms of demographic variables.

Design/methodology/approach - In the study, which was used in the descriptive survey model, a 3part questionnaire was used as data collection tool. The sample of the study consisted of 332 bank staff working in the banks operating in the province of Kars. The applied survey technique was used in the study. In the study Pearson correlation analysis, simple linear regression analysis, independent sample $t$ test and one-way ANOVA analysis were used.

Findings - As a result of the analyzes, a statistically significant, weak and positive relationship was determined between career commitment levels and subjective career success perceptions. of the working employee in the banks. Furthermore, according to the results of the research, career commitment levels of bank employees positively affect subjective perceptions of career success. However, it was concluded that subjective career success differed in terms of demographic variables such as gender, age, department they worked in, sector working time, and did not differ in demographic variables such as marital status and education level.

Discussion - One of the main goals of the employees' working lives is to be successful in their careers. Career commitment is a variable that is effective in career success. The studies show that employees who depend on their careers tend to be more successful in their careers. More 
comprehensive research in the future may contribute to the literature. In addition, researchers are advised to examine the determinants of career success, particularly in different sectors or in the banking sector with a larger sample size. By identifying these determinants, it is thought that organizations can produce policies that increase the productivity of both their employees and the organization.

\section{Giriş}

İşverenler; küreselleşme eğilimleri ve teknolojik gelişmelerden kaynaklanan değişen çevre koşulları nedeniyle mükemmeliyetçi yaklaşımı benimsemişlerdir. Çalışanlarsa bu yeni gerçekliğe uyum sağlamak için yeni kariyer stratejileri ve davranışları geliştirmeye başlamışlardır (Ballout, 2009: 655).

Kariyer başarısı kavramı son yıllarda giderek önem kazanmaktadır. Çünkü bireyin kariyerinin genel bir değerlendirmesini yansıtır. Kariyer başarısı kişisel iş deneyimlerinin bir sonucudur. Kariyer başarısı; deneyim ve gerçek ya da algılanan başarının birikimi olarak görülmektedir. Aslında kişinin bakış açısında maddi gelişim, güç, mutluluk ve tatmin kaynağı olarak algılanmaktadır (Yu, 2012: 89). Kariyer başarısı sadece çalışanlar için değil örgütler için de önemlidir. Çünkü çalışanların kişisel başarısı örgütün başarısına da katkı sağlamaktadır. Bu sebeple kariyer başarısı elde eden çalışanların mevcut işletmede kalması örgüt tarafından da istenen bir durumdur (Otçuoğlu, 2014: 351).

Kariyer başarısı araştırmacılar tarafından son derece önemsenen konular arasındadır. Başka bir ifade ile çalışanların kariyer başarısı, ortaya çıktığı günden bu yana birçok bilim adamının çalışmalarında odaklandıkları bir terim olmuştur (Amin vd., 2017: 2). Alan yazın incelendiğinde yapılan araştırmaların bir kısmı kariyer başarısını bireylerin kariyerlerini nasıl etkilediği ve kariyer başarısının algılanma düzeyi konusunda önemli etkiye sahip olan birkaç bireysel farklılık faktörü açısından açıklamaya yöneliktir. Kariyer başarısı ile ilişkili olarak belirlenen bireysel düzey belirleyicileri arasında çalışanların demografik özellikleri (cinsiyet, medeni durum, yaş, statü, ırk, vb) (Eddleston vd., 2004; Greenhaus ve Parasuman 1993; Sturges 1999), beşeri sermaye (iş deneyimi, kıdem, eğitim seviyesi, beceriler, bilgi ve donanım) (Ballout 2009; Judge vd., 1995; Wayne vd., 1999), kişisel özellikler (kişilik, kontrol odağı vb) (Boudreau vd., 2001; Sutin vd., 2009) olarak açıklanmıştır.

Kariyer başarısını belirleyen kişisel faktörler başlığı altında ele alınabilecek bir diğer değişken ise kariyer bağlılığıdır. Çalışanların kariyer başarısını belirleyen potansiyel öncüllerden biri olan kariyer bağlılığı, bir kişinin kariyer planlamasına ne derece değer verdiği ve kariyer hedeflerini yerine getirme şekli olarak tanımlanmaktadır (Chung, 2002: 278). Yapılan bir çalışmada kariyer bağlılığı yüksek olan çalışanların kendi kariyer hedeflerini geliştirme ve sürdürme eğilimlerinin oldukça yüksek olduğu ortaya çıkmıştır (Yan, 2005: 44-45). Kariyer bağlılığı günümüzde yaşanan istikrarsız ve çalışma güvencesinden yoksun iş koşullarında çalışanların sahip çıkmaları gereken bir tutumdur. Bu güvencesiz çalışma koşullarında birey gerektiğinde çalıştığı örgütü değiştirerek iş hayatında kalmaya çabalarken, mevcut örgütünden daha çok kendi kariyerine bağlanmak ve güvenmek zorunda olduğu söylenebilmektedir.

İş güvenliği, hizmet içi eğitimler, kariyer geliştirme programları örgütler tarafından çalışanın kariyerini yöneten ve kariyerinde başarılı olmasını sağlayan faaliyetlerdir (Yean ve Yahya, 2013: 194). Ancak işverenler, küçülme yoluna gittiklerinde verdikleri çeşitli hakları geri almak, eğitim ve gelişim programlarına ve diğer insan kaynakları faaliyetlerine yatırdıkları fonları kısıtlamak durumunda kalabilirler. Bu da çalışanlarda tatminsizlik, depresyon ve umutsuzluk gibi olumsuz duygu durumlarına neden olabilmektedir. Sonuç olarak çalışanların kariyer başarılarını tamamen tehlikeye atabilmektedir (Pasha vd., 2017: 186).

Çalışanların kariyer başarısını belirleyen faktörlerden biri de kariyer bağlılı̆̆ıdır. Kariyer bağlılığı çalışanın kendi kariyerini geliştirmek ve ilerletmek istediği seviyeye işaret ettiği için kariyer bağlılığı ile kariyer başarısı arasında bir ilişki olduğu düşünüldüğünden bu çalışma kariyer bağlıllı̆g ve kariyer başarısı arasındaki bağlantıyı incelemek amacıyla yapılmıştır. Buna ek olarak bu çalışmanın bir diğer amacı da banka çalışanlarının demografik özelliklerin öznel kariyer başarı düzeyleri açısından farklılıklarını incelemektir.

\section{Kavramsal Çerçeve}

\subsection{Kariyer Bă̆glı̆ı̆ $\imath$}

Kariyer, kişiye ömrü boyunca düzenlenmiş iş dizisi; kişide meydana gelen iş, meslek ve pozisyon değişikliği 
ve kişinin bu değişikliklere olan tutumunu da kapsamaktadır (Yang, 2011: 366). Kariyer bağl1lığı çalışanın işlerini yapma motivasyonunu yansıtmaktadır. Bir kişinin belli bir mesleğe ya da işine olan tutumudur. Kariyer bağllığı geniş anlamda işe olan bağlılık olarak ifade edilmektedir (Blau, 1985: 279).

1950 'lerden bu yana iş yerinde bağlılık kavramı bir takım akademisyenler ve uygulayıcıların dikkatini çekmektedir. Kariyer bağlllığ1 olgusunu anlamak için çeşitli kavramsallaştırmalar önerilmiştir (Cohen, 2003: 152). Örneğin Becker ve Carper (1956) kariyer bağlllığının önemini göstermek için yan-bahis (side-bet) teorisini geliştirmişlerdir. Yan-bahis teorisine göre;

"ișletmeye bağlllık kişinin örgüte hizmet verdiği süre boyunca harcadığı zaman, emek, çaba ve karşılığında kazandığı para ve statü gibi değerleri örgütten ayrıldığı zaman kaybedeceği ve bütün yaptıklarının boşa gideceği korkusu sonucu oluşan bir bağll1ıktır" (akt. Gökmen, 1996: 1-2). Bir başka öncü çalışma ise bireyin çalışmasına anlam ve önem verdiği ölçüde "kariyer ilgisini" tanımlayan Greenhaus'un (1971) çalışmasıdır. Greerhaus (1971)'a göre genel anlamıyla kariyer bağlılığı kişinin mesleğine olan tavrıdır. Bu tavır kişisel bir anlam içermektedir (akt. Carmelli ve Gefen, 2005: 8). Kariyer bağlllı̆̆ı, bireysel kariyer hedeflerinde güçlü bir kimlik, ikna, gelişme ve aktif katılım duygusu ile karakterize edilmektedir. Başka bir ifade ile kariyer bağl1lı̆̆ı kişinin kariyer hedeflerine olan bağlılığıdır (Corelli ve Bishop, 1990: 160).

\section{2. Öznel Kariyer Başarısı}

Kariyer başarısı bir kişinin iş deneyimi sonucu biriktirdiği başarılarıdır ya da kişinin işle ilgili elde ettiği pozitif psikolojik sonuçlardır (Judge vd., 1995: 486). Başka bir ifade ile kariyer başarısı bireylerin iş deneyimleri sonucunda elde ettikleri gerçek veya algılanan başarılarının toplamıdır (Judge vd., 1995: 486). Kariyer başarısı çalışanların kariyer deneyimlerinin sonucuna odaklanmaktadır. Kariyer başarısı çalışanların kariyer uygulamalarına, sektöre olan katkılarına, işlerine olan bağllıklarına ve işlerindeki başarılarına bağlıdır (Hennekam, 1996: 17).

Kariyer başarısının iki boyutu vardır: dış veya nesnel kariyer başarısı ve öznel veya iç kariyer başarısı. Nesnel kariyer başarısı, ödeme (maaş) gibi ölçülebilir ve doğrulanabilir kazançlar ile ilgilidir. Öznel kariyer başarısı ise bireyin kendi kariyer deneyimlerine verdiği tepkiler olarak tanımlanmaktadır (Heslin, 2005: 114). Nesnel kariyer başarısı bireyin mevcut kariyer durumunu sosyal kabul edilebilen başarı kriterlerine göre değerlendirmek için dışarıdan bir bakış açısı içerirken öznel kariyer başarısı bireyin kariyer deneyimlerini ortaya çıkarma konusundaki tepkisini yakalar. Bireyin kariyer istekleri ve işle ilgili sonuçlarına atıfta bulunur (Biemann ve Braakmann, 2013: 3440). Bu çalışmada kariyer başarısının öznel kariyer başarısı boyutu incelenmiştir. Öznel kariyer başarısı, bireyin içsel algısını ve bireyin kendisi tarafından algılanan herhangi bir boyutta kendi kariyerini değerlendirmesini yansitmaktadır (Arthur vd., 2005: 178).

\subsection{Literatür Taraması}

Kariyer başarısı ile ilgili alan yazın incelendiğinde öznel kariyer başarısı ile en çok ilişkilendirilen konu kariyer bağlllığıdır. Sultana vd. (2016), Day ve Allen (2004) ve Otçuoğlu (2014) çalışmalarında kariyer başarısının iki boyutu (öznel ve nesnel kariyer başarısı) ile kariyer bağlılıkları arasında pozitif yönlü anlamlı ilişkiler tespit etmişlerdir. Araştırmaların sonuçlarında kariyerlerine bağlı olan çalışanların bağlı olmayanlara kıyasla daha yüksek ücrete, statüye ve terfi sayılarına sahip oldukları görülmüştür. Buna ek olarak bu sonuç kariyerlerine bağlı olan katılımcıların kariyerleri üzerinde daha iyi kontrol sahibi olduklarını, hem nesnel hem de öznel olarak daha başarılı olabileceklerini göstermektedir.

Kariyer başarısını öngörmede kariyer bağlılığının önemli bir belirleyici olduğu söylenebilmektedir. Bireysel başarı örgütsel başarıyı teşvik etmekte ve bu durum çalışanların bağlılık düzeyini artırmaktadır (Amin ve diğ., 2017). Bu doğrultuda Poon (2004) yaptığı araştırma ile kariyer bağlllı̆̆ının artması durumunda çalışanın kendi kariyerini geliştirme ve bu yolda ilerleme isteğini artıracağını ileri sürmüştür.

Kariyer bağlılığı çeşitli yollardan bireylerin kariyer başarılarını desteklemektedir. Yapılan çalışmalar kariyerlerine bağlı bireylerin, daha fazla çaba sarf ettiğini ve yeni bilgi ve beceriler kazanmaları bakımından kariyerlerine önemli ölçüde yatırım yaptıklarını göstermektedir. Araştırmaların sonuçlarına göre kariyer bağlılık seviyesi ne kadar yüksek olursa işe karşı tutum o kadar olumlu olmaktadır ki o da kariyer başarısını etkilemektedir (Aryee vd., 1994; Rashid ve Zao, 2010).

Alan yazında kariyer bağlılığının kariyer motivasyonunu artırdığını, kariyer motivasyonu yüksek olan 
çalışanların kariyer hedeflerine daha fazla yoğunlaştıklarına ilişkin çalışmalar mevcuttur (Ballout, 2009; Corelli ve Bishop, 1990). Çalışmaların sonuçlarına göre kariyerlerine bağlı olan kişiler her türlü zor durum ve koşulda kariyer hedeflerini gerçekleştirebilmek için en iyi şekilde çalışmak ve deneyim elde edebilmek için motive olmuşlardır.

Kariyer başarısını belirleyen faktörlerden bir diğeri de kişisel faktörlerdir. Çalışanların demografik özelliklerinin ve mesleki niteliklerinin kariyer başarıları üzerindeki rolü özellikle yabancı araştırmacılar tarafından araştırma konusu olarak görülmüştür. Yapılan ampirik çalışmalar çalışanların demografik özellikleri gibi kariyer başarısı ile ilgili değişkenleri belirleyerek bu sorunu ele almışlardır (Greenhaus and Parasuraman, 1993; Stroh, vd., 1992; Tharenou vd., 1994). Araştırmacılar kariyer başarısı kavramında ihtiyaç duyulan gündemin kariyer başarısının birçok belirleyicisini incelemek olduğunu öne sürmüşlerdir (Judge vd., 1995). Bazı araştırmacılar (Aryee vd., 1994; Judge vd., 1995; Sheridon vd., 1997; Stroh vd., 1992, Tharenou vd., 1994) eğitim düzeyi, iş deneyimi, kıdem, işle ilgili bilgi ve beceriler gibi belirleyicileri "insan sermayesi" olarak adlandırmışlardır. Bununla birlikte bazı araştırmacılar da (Chenevert ve Trembley, 2002; Ballout, 2009; Wayne vd., 1999; Eddleston vd., 2004; Sturges, 1999) cinsiyet, yaş, sosyo-ekonomik statü, 1rk, medeni durum gibi belirleyicileri "sosyo-demografik özellikler" olarak açıklamışlardır.

Kariyer bağlılı̆gı ve kariyer başarısı kavramları ile ilgili uluslararası yazında yapılmış birçok araştırma bulunmaktadır. Ancak bankacılık sektöründe kariyer bağlılığı ile sübjektif (öznel) kariyer başarısı ve demografik özelliklere ilişkin ilişkilerin araştırıldığı bir çalışmaya henüz rastlanmamıştır. Bu araştırmanın amacı, banka çalışanlarının kariyer bağlılık düzeylerinin öznel kariyer başarısı algıları üzerinde etkisini incelemek ve çalışanların öznel kariyer başarısı algılarının demografik özellikler bakımından farklılaşmasını tespit etmektir. Bu amaç doğrultusunda aşağıdaki hipotezler geliştirilmiştir:

Hı: Çalışanların kariyer bağlılık düzeyleri öznel kariyer başarısı algılarını pozitif yönde etkilemektedir.

$\mathbf{H}_{2}$ : Öznel kariyer başarısı algısı çalışanların cinsiyetine göre farklılık gösterir.

$\mathbf{H}_{3}$ : Öznel kariyer başarısı algısı çalışanların medeni durumuna göre farklılık gösterir.

$\mathrm{H}_{4}$ : Öznel kariyer başarısı algısı çalışanların yaşına göre farklılık gösterir.

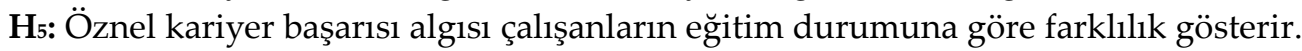

H6: Öznel kariyer başarısı algısı çalışanların görev yaptıkları departmanlara göre farklılık gösterir.

H7: Öznel kariyer başarısı algısı çalışanların sektördeki çalışma sürelerine göre farklılık gösterir.

\section{Yöntem}

\subsection{Araștırmanın Modeli}

$\mathrm{Bu}$ araştırmada nicel araştırma türlerinden tarama (betimsel) modeli kullanılmıştır. Karasar (2012) tarama (betimsel) modelini, geçmişte veya günümüzdeki bir duruma yönelik herhangi bir değişiklik yapmadan içinde bulunduğu şartlara bağlı kalarak ve aslına uygun şekilde yalnızca gözlemleyip betimlemeyi amaçlayan araştırma yaklaşımı olarak tanımlamaktadır.

\subsection{Araştırmanın Evreni ve Örneklemi}

Araştırmanın örneklemini Kars ilinde ve ilçelerinde faaliyet gösteren banka şubeleri çalışanları oluşturmaktadır. Araştırmada kolayda örnekleme yöntemi kullanılmıştır.

Banka şubelerinin müdürleri ile araştırma konusu ile ilgili ön görüşmeler yapılmış bununla birlikte çalışan sayılarına ilişkin bilgiler şube müdürlerinden alınmıştır. Banka şubelerine bütün çalışanları kapsayacak şekilde 400 adet anket bırakılmıştır. Belli bir süre sonra 351 anket geri toplanmıştır. Ancak soru formuna tam olarak cevap verilmemesi nedeniyle anket formlarının bir kısmı araştırmaya dâhil edilmemiştir. Araştırmada kullanılabilecek anket sayısı 332' dır.

\section{3. Çalışma Grubu}

Araştırma Kars ilinde hizmet veren kamu ve özel bankaların şubelerinde çalışan personele yönelik yürütülmüştür. Tablo 1'de araştırmaya katılan banka çalışanlarının demografik özelliklerine ilişkin bilgiler bulunmaktadır. 
Tablo 1. Banka Çalışanlarının Demografik Özellikleri

\begin{tabular}{|c|c|c|c|c|c|c|c|}
\hline & & $\mathbf{N}$ & $\%$ & & & $\mathbf{N}$ & $\%$ \\
\hline \multirow{3}{*}{ Cinsiyet } & Kadın & 139 & 41,9 & \multirow{3}{*}{$\begin{array}{l}\text { Medeni } \\
\text { Durum }\end{array}$} & Evli & 191 & 57,5 \\
\hline & Erkek & 193 & 58,1 & & Bekâr & 139 & 41,9 \\
\hline & Toplam & 332 & 100,0 & & Toplam & 332 & 100,0 \\
\hline \multirow{5}{*}{ Yaş } & $18-24$ & 30 & 9,0 & \multirow{5}{*}{$\begin{array}{l}\text { Eğitim } \\
\text { Düzeyi }\end{array}$} & Lise & 24 & 7,2 \\
\hline & $25-34$ & 187 & 56,3 & & Önlisans & 42 & 12,7 \\
\hline & $35-44$ & 100 & 31,1 & & Lisans & 234 & 70,5 \\
\hline & $45-54$ & 15 & 4,5 & & Yüksek Lisans & 32 & 9,6 \\
\hline & Toplam & 332 & 100,0 & & Toplam & 332 & 100,0 \\
\hline \multirow{10}{*}{$\begin{array}{l}\text { Görev } \\
\text { Yaptıkları } \\
\text { Departmanlar }\end{array}$} & Operasyon & 122 & 36,7 & \multirow{10}{*}{$\begin{array}{l}\text { Sektörde } \\
\text { Çalışma } \\
\text { Süresi }\end{array}$} & 1 yıldan az & 33 & 9,9 \\
\hline & Bireysel & 91 & 27,4 & & $1-5$ yıl & 124 & 37,3 \\
\hline & İşletme & 24 & 7,2 & & 6-10 yıl & 100 & 30,1 \\
\hline & Kobi & 36 & 10,8 & & $11-15$ yil & 54 & 16,3 \\
\hline & Obi & 6 & 1,8 & & 16 yıl ve üzeri & 21 & 6,3 \\
\hline & Sigorta & 4 & 1,2 & & Toplam & 332 & 100,0 \\
\hline & Güvenlik & 18 & 5,4 & & & & \\
\hline & Tarım & 20 & 6,0 & & & & \\
\hline & $\begin{array}{l}\text { Yönetici } \\
\text { (Şube } \\
\text { Müdürü) }\end{array}$ & 11 & 3,3 & & & & \\
\hline & Toplam & 332 & 100,0 & & & & \\
\hline
\end{tabular}

Tablo 1 de görüldüğü üzere katılımcıların \%58,1'i erkek, \%57,5'i evlidir. Çalışanların \%56,3'ü 25-34 yaş aralığında, \%70,5'i lisans mezunudur. Katılımcıların \%36,7'si operasyon departmanında ve \%30,1'i 1-5 yıldır bankacılık sektöründe çalışmaktadır.

\subsection{Veri Toplama Araçları}

Anket formu üç bölümden oluşmaktadır. Birinci bölümde Blau (1985) tarafından geliştirilen 8 ifadeden oluşan Kariyer Bağl1lı̆̆ı Ölçeği, ikinci bölümde Turban ve Dougherty (1994) tarafından geliştirilen 4 ifadeden oluşan Öznel Kariyer Başarısı Ölçeği'dir. Son bölümde katılımcıların demografik özelliklerine ilişkin 9 adet soru bulunmaktadır. Araştırmada 5'li Likert tipi ölçek kullanılmıştır.

Güvenilirlik "bir testin veya ölçeğin ölçmek istediği şeyi tutarlı ve istikrarlı bir biçimde ölçme derecesi" dir (Altunışık ve Diğ., 2005, s. 114). Ölçümlerin tekrarlanması halinde ortaya çıan tutarlı sonuçlardır (Nakip, 2013, s. 203). Güvenilirliği ölçmeye yönelik en yaygın olarak kullanılan Cronbach Alpha katsayısıdır (Kalaycı, 2010, s. 405; Özdamar, 2002, s. 622). Ölçeğin genel güvenilirliğine ve içsel tutarlılı̆̆ına işaret etmekte olan Cronbach Alpha katsayısı maddelerin varyansları toplamının genel varyansa ortalaması sonucu elde edilen ağırlıkı standart değişim ortalamasıdır ve 0-1 arası değer almaktadır (Gürbüz ve Şahin, 2017, s. 329). Cronbach Alpha katsayısının 0,60 ile 0,80 arasında olması ölçeğin oldukça güvenilir olduğuna, katsayının 0,80 ile 1.00 arasında olması ise ölçeğin yüksek derecede güvenilir olduğuna işaret etmektedir (Kalaycı, 2010, s. 405).

Bankacılık sektöründe çalışanların kariyer bağlılıklarının öznel kariyer başarılarına olan etkilerini ve demografik özelliklerine göre farklılaşmalarını ölçmek amacıyla kullanılan ölçekler anket formu ile banka çalışanlarına sorulmuştur. Araştırmada kullanılan ölçekler İngilizce 'den Türkçe 'ye çevrilmiştir. Kurumda çalışan İngilizce okutmanları ile birlikte bankacılık sektöründe pilot araştırma $(n=30)$ vasıtasıyla gözden geçirilmiş ve anlam kaymaları önlenmeye çalışılmıştır. Türkiye'de başka bir araştırma kapsamında uygulaması yapılmış olan kariyer bağlılığı ölçeğinin güvenilirlik düzeyi 0.82 , kariyer başarısı ölçeğinin güvenilirlik düzeyi ise $0.88^{\prime}$ dir (Karavardar, 2014). 
Çalışma kapsamında kullanılan ölçeklerinin uygulanması sonucunda elde edilen puanlara ilişkin güvenirlik kestirimleri amacıyla hesaplanan Cronbach alfa iç tutarlılık katsayıları Tablo 2' de sunulmuştur.

Tablo 2. Ölçeklerin Güvenilirlik Katsayıları
Ölçekler
Madde Sayısı
Cronbach Alpha

\begin{tabular}{lcc}
\hline Kariyer Bağlılığı & 8 & 0,835 \\
\hline Öznel Kariyer Başarısı & 3 & 0,763 \\
\hline
\end{tabular}

Çalışmada banka çalışanlarının kariyer bağlılıklarını ölçmek amacıyla Kariyer Bağlılık Ölçeği, kariyerlerindeki başarılarını ölçmek için Öznel Kariyer Başarısı Ölçeği Geliştirilen ölçeklerin tek boyutlu olmasını sağlamak adına ölçeklere keşfedici faktör analizi yapılmıştır. Ölçeklerin temel bileşenler analizi ile ortaya konulan faktör yapıları Tablo 3'de sunulmuştur. Öznel kariyer başarısına ait 3. ifadenin faktör yükü 0,30'dan küçük $(0,096)$ olduğu için ölçekten çıkarılmıştır.

Tablo 3. Temel Bileşen Analizi Kullanılarak Yapılan Faktör Analizi Sonuçları

\begin{tabular}{|c|c|c|c|c|}
\hline İfadeler & Etken Varyans & Özdeğerler & $\begin{array}{l}\text { Açlklanan Varyans } \\
\text { Yüzdesi (\%) }\end{array}$ & $\begin{array}{l}\text { Toplam Açıklanan } \\
\text { Varyans Yüzdesi (\%) }\end{array}$ \\
\hline KBağ1* & 0,691 & 3,972 & 49,649 & 49,649 \\
\hline KBağ2 & 0,558 & 1,303 & 16,286 & 65,935 \\
\hline KBağ3* & 0,714 & 0691 & 8,635 & 74,570 \\
\hline KBağ4 & 0,584 & 0,616 & 7,698 & 82,268 \\
\hline KBağ5 & 0,732 & 0,460 & 5,752 & 88,019 \\
\hline KBağ6 & 0,771 & 0,440 & 5,498 & 93,518 \\
\hline KBağ7 & 0,744 & 0,305 & 3,812 & 97,329 \\
\hline KBağ8 & 0,481 & 0,214 & 2,671 & 100,000 \\
\hline ÖKB1 & 0,769 & 2,059 & 68,628 & 68,628 \\
\hline ÖKB2 & 0,817 & 0,690 & 22,985 & 91,614 \\
\hline ÖKB4 & 0,473 & 0,252 & 8,386 & 100,000 \\
\hline
\end{tabular}

Not * ifadeler ters kodlanmıştır.

KBağ: Kariyer Bağlılı̆̆ı, ÖKB: Öznel Kariyer Başarısı.

\section{Bulgular}

Araştırmanın değişkenlerine ait ortalama, standart sapma ve korelasyon katsayıları Tablo 4'te yer almıştır.

Tablo 4. Araştırmanın Değişkenlerine İlişkin Ortalama, Standart Sapma ve Korelasyon Katsayıları

\begin{tabular}{llll}
\hline Değişkenler & Ortalama & S.S. & $\mathbf{1}$ \\
\hline Kariyer Bağlı̆ı̆̆1 & 2,69 & 0,97 & - \\
\hline Öznel Kariyer Başarısı & 3,57 & 0,83 & $0,260^{* *}$ \\
\hline
\end{tabular}

${ }^{*} \mathrm{P}<0,05$ (iki uçlu), ${ }^{* *} \mathrm{p}<0,01$ (iki uçlu)

Elde edilen bulgular neticesinde banka çalışanlarının bağlılığı ile öznel kariyer başarısı arasında istatistiksel açıdan anlamlı zayıf ve pozitif yönlü bir ilişki $(\mathrm{r}(332)=0,260, \mathrm{p}<0,01)$ bulunduğu gözlenmektedir.

Tablo 5. Kariyer Bağlılığının Öznel Kariyer Başarısı Üzerindeki Etkisine İlişkin Regresyon Analizi

\begin{tabular}{|c|c|c|c|c|c|c|c|c|c|}
\hline $\begin{array}{l}\text { Bağımlı } \\
\text { Değişken }\end{array}$ & $\begin{array}{l}\text { Bağımsız } \\
\text { Değişken }\end{array}$ & $\beta$ & B & $\begin{array}{l}\text { Std. } \\
\text { Hata }\end{array}$ & $\mathbf{t}$ & $\mathbf{R}^{2}$ & A. $R^{2}$ & $\mathbf{F}$ & $p$ \\
\hline \multicolumn{10}{|l|}{$\begin{array}{l}\text { Öznel } \\
\text { Kariyer } \\
\text { Başarısı }\end{array}$} \\
\hline & $\begin{array}{l}\text { Kariyer } \\
\text { Bağlılığ }\end{array}$ & 0,318 & 0,355 & 0,169 & 11,093 & 0,126 & 0,123 & 47,483 & $0,000^{* *}$ \\
\hline
\end{tabular}

${ }^{*} \mathrm{P}<0,05$ (iki uçlu), ${ }^{* *} \mathrm{p}<0,001$ (iki uçlu) 
Banka çalışanlarının kariyer bağlılık düzeylerinin öznel kariyer başarıları üzerindeki etkisine ilişkin basit doğrusal regresyon analizi yapılmıştır. Tablo 5 'de yer alan basit regresyon analizi sonuçları istatistiksel açıdan anlamlıdır $[\mathrm{F}(1,330)=47,483, \mathrm{p}<0,001]$. Analiz sonuçlarına göre banka çalışanlarının kariyer bağlılık düzeyleri öznel kariyer başarıları algılarını pozitif yönlü etkilemektedir $[\beta=0,318, p<0,001]$. Ayrıca düzeltilmiş $\mathrm{R}^{2}$ değeri 0,123'dür. Bu değere göre kariyer başarısındaki \%12'lik varyansın kariyer bağlılığı düzeyi ile açıklandığı görülmektedir. Dolayısı ile H1 hipotezi desteklenmektedir.

Çalışmada öznel kariyer başarısının değişik demografik özelliklere göre farklılıklar gösterip göstermediği yapılan bağımsız örneklem $t$ testi ve tek yönlü ANOVA analizleri ile ortaya çıkarılmaya çalışılmıştır.

Tablo 6. Bankacılık Sektöründe Çalışanların Cinsiyete Göre Öznel Kariyer Başarısı Bağımsız Örneklemler t Testi Analizi

\begin{tabular}{|c|c|c|c|c|c|c|}
\hline Cinsiyet & $\mathbf{N}$ & A. Ort & S.S. & S.D. & $\mathbf{t}$ & $\mathrm{p}$ \\
\hline Kadın & 139 & 3,412 & 0,80915 & 303 & $-2,973$ & $0,003^{*}$ \\
\hline Erkek & 193 & 3,683 & 0,83662 & & & \\
\hline
\end{tabular}

Tablo 6'da çalışanların cinsiyetlerine göre kadınlar ve erkekler arasında öznel kariyer başarısı algısı bakımından yapılan bağımsız örneklem $t$ testi sonuçları yer almaktadır. Buna göre banka çalışanlarının öznel kariyer başarısına ilişkin algıları arasında cinsiyetleri bakımından anlamlı bir farklılık bulunmuştur (t $(303)=-2,973 ; p<0,05)$. Erkek çalışanların öznel kariyer başarısına ilişkin görüşlerinin ortalaması (Ort.= 3,68; S.S.= 0,83) kadın çalışanların öznel kariyer başarılarına ilişkin görüşlerin ortalamasından (Ort.= 3,41; S.S.= 0,81 ) biraz daha yüksek çıkmıştır. Bu sonuçlar erkek çalışanların kadın çalışanlardan daha fazla öznel kariyer başarısı algısına sahip olduklarını göstermektedir. Bağımsız örneklem $t$ testi sonucuna göre H2 hipotezi desteklenmektedir. Başka bir ifade ile kadın ve erkek banka çalışanlarının öznel kariyer başarısına ilişkin algılarında anlamlı bir farklılık bulunmaktadır.

Tablo 7. Bankacılık Sektöründe Çalışanların Medeni Duruma Göre Öznel Kariyer Başarısı Bağımsız Örneklemler t Testi Analizi

\begin{tabular}{|c|c|c|c|c|c|c|}
\hline Medeni Durum & $\mathbf{N}$ & A. Ort & S.S. & S.D. & $\mathbf{t}$ & p \\
\hline Evli & 191 & 3,6213 & 0,83996 & 304,596 & 1,300 & 0,195 \\
\hline Bekâr & 141 & 3,5012 & 0,82580 & & & \\
\hline
\end{tabular}

Tablo 7'de görüldüğü üzere evli çalışanlar ile bekâr çalışanların öznel kariyer başarıları algılarına ilişkin yapılan bağımsız örneklem $t$ testi sonuçları istatistiksel açıdan anlamlı olmadığından $(p>0,05)$ H3 hipotezi desteklenmemiştir. Öznel kariyer başarısı algısı çalışanların medeni durumlarına göre farklılık göstermemektedir.

Tablo 8. Bankacılık Sektöründe Çalışanların Yaşlarına İlişkin Bazı İstatistikler

\begin{tabular}{llll}
\hline Çalışanların Yaş Durumu & $\mathbf{N}$ & A.Ort & S.S. \\
\hline $\mathbf{1 8 - 2 4}$ yaş & 30 & 3,2889 & 0,97373 \\
\hline $\mathbf{2 5 - 3 4}$ yaş & 187 & 3,5455 & 0,77878 \\
\hline $\mathbf{3 5 - 4 4}$ yaş & 100 & 3,6067 & 0,89566 \\
\hline $\mathbf{4 5 - 5 4}$ yaş & 15 & 4,2000 & 0,41404 \\
\hline Toplam & 332 & 3,5703 & 0,83484 \\
\hline
\end{tabular}

Tablo 8'de katılımcıların öznel kariyer başarısına ilişkin algılarının orta düzeyli olduğu görülmektedir. Yaşa göre öznel kariyer başarısına yönelik algılarının farklılaşıp farklılaşmadığına yönelik ANOVA sonuçları Tablo 9'da sunulmuştur. 
Tablo 9. Bankacılık Sektöründe Çalışanların Yaşlarına Göre Öznel Kariyer Başarısı Tek Yönlü ANOVA Analizi

\begin{tabular}{llllll}
\hline & $\begin{array}{l}\text { Kareler } \\
\text { Toplami }\end{array}$ & sd & $\begin{array}{l}\text { Kareler } \\
\text { Ortalaması }\end{array}$ & F & p \\
\hline Gruplar arasi & 8,571 & 3 & 2,857 & 4,219 & 0,006 \\
\hline Grup içi & 222,122 & 328 &, 677 & & \\
\hline Toplam & 230,693 & 331 & & \\
\hline
\end{tabular}

Tek yönlü ANOVA analizi sonuçlarına göre farklı yaş aralı̆̆ına sahip kişilerin öznel kariyer başarısına ilişkin algıları arasında anlamlı bir farklılık bulunmaktadır ( $F(3,328)=4,219 ; \mathrm{p}<0,05)$. Başka bir ifade ile öznel kariyer başarısı algısı katılımcıların yaşına göre farklılık göstermektedir. Bu durumda $\mathbf{H 4}$ hipotezi desteklenmektedir. Farklılıkların hangi gruplardan kaynaklandığını bulmak için çoklu karşılaştırma Tukey testi yapılmıştır. Test sonuçlarında farklılıkların 45-54 yaş grubu çalışanlardan kaynaklandığı, 45-54 yaş grubu çalışanların öznel kariyer başarısı algıları ile diğer 18-24 yaş, 25-34 yaş ve 35-44 yaş çalışanların öznel kariyer başarısı algıları arasında istatistiksel açıdan anlamlı bir farklılık olduğu tespit edilmiştir. Çalışanların yaşları bakımından öznel kariyer başarısı algılarının ortalamalarına bakıldığında ise 18-24 yaş (Ort.= 3,29; S.S.= 0,97$)$, $25-34$ yaş $($ Ort. $=3,54$; S.S. $=0,78)$, 35-44 yaş $($ Ort. $=3,61$; S.S. $=0,90)$ ve $45-54$ yaş $($ Ort. $=4,20$; S.S.= 0,83 ) olduğu görülmektedir.

Tablo 10. Bankacılık Sektöründe Çalışanların Eğitim Düzeyine İlişkin Bazı İstatistikler

\begin{tabular}{llll}
\hline Çalışanların Yaş Durumu & N & A. Ort & S.S. \\
\hline Lise & 30 & 3,2889 & 0,97373 \\
\hline Önlisans & 187 & 3,5455 & 0,77878 \\
\hline Lisans & 100 & 3,6067 & 0,89566 \\
\hline Yüksek Lisans & 15 & 4,2000 & 0,41404 \\
\hline Total & 332 & 3,5703 & 0,83484 \\
\hline
\end{tabular}

Araştırmaya katılan farklı eğitim düzeyine sahip banka çalışanlarının öznel kariyer başarısı algılarına ilişkin bazı istatistikler Tablo 10'da yer almaktadır. Tablo 10'da katılımcıların eğitim durumları bakımından öznel başarı algısı ortalamalarına bakıldığında katılımcıların eğitim düzeyi arttıkça (Lise Ort.= 3,28; Önlisans Ort.= 3,54; Lisans Ort. $=3,60$; Yüksek Lisans Ort. $=4,20)$ öznel kariyer başarısı algılarının da yükseldiğini görmekteyiz. En düşük ortalama lise mezunu olan katılımcllarda bulunurken en yüksek ortalama yüksek lisans düzeyindeki katılımcilarda bulunmaktadır.

Tablo 11. Bankacılık Sektöründe Çalışanların Eğitim Düzeyine Göre Öznel Kariyer Başarısı Tek Yönlü ANOVA Analizi

\begin{tabular}{llllll}
\hline & $\begin{array}{l}\text { Kareler } \\
\text { Toplamı }\end{array}$ & sd & $\begin{array}{l}\text { Kareler } \\
\text { Ortalaması }\end{array}$ & F & p \\
\hline Gruplar arası & 1,254 & 3 & 0,418 & 0,597 & 0,617 \\
\hline Grup içi & 229,440 & 328 & 0,700 & & \\
\hline Toplam & 230,693 & 331 & & & \\
\hline
\end{tabular}

Tablo 11'de katılımcıların öznel kariyer başarısı algılarının eğitim düzeylerine göre farklılaşıp farklılaşmadığını gösteren tek yönlü ANOVA analizinin sonuçları sunulmuştur. Bu sonuçlara göre eğitim açısından katılımcların öznel kariyer başarıları algılarında anlamlı bir farklılık bulunmamaktadır ( $>00,05)$. Dolayısı ile $\mathbf{H} 5$ hipotezi desteklenememiştir. 
Tablo 12. Bankacılık Sektöründeki Çalışanların Görev Yaptıkları Departmanlara İlişkin Bazı İstatistikler

\begin{tabular}{lccc}
\hline Çalışanların Görev Yaptıkları Departman Durumu & $\mathbf{N}$ & A.Ort & S.S. \\
\hline Operasyon & 122 & 3,3333 & 0,80859 \\
\hline Bireysel & 91 & 3,5714 & 0,96005 \\
\hline İşletme & 24 & 3,5833 & 0,85832 \\
\hline Kobi & 36 & 3,7963 & 0,63884 \\
\hline Obi & 6 & 4,2222 & 0,75031 \\
\hline Sigorta & 4 & 4,0000 & 0,00000 \\
\hline Güvenlik & 18 & 3,8148 & 0,58547 \\
\hline Tarım & 20 & 3,6333 & 0,53966 \\
\hline Yönetici (Şube Müdürü) & 11 & 4,3939 & 0,51247 \\
\hline Total & 332 & 3,5703 & 0,83484 \\
\hline
\end{tabular}

Tablo 13. Bankacılık Sektöründe Çalışanların Departman Türlerine Göre Öznel Kariyer Başarısı Tek Yönlü ANOVA Analizi

\begin{tabular}{lrrccc}
\hline & $\begin{array}{c}\text { Kareler } \\
\text { Toplamı }\end{array}$ & sd & $\begin{array}{c}\text { Kareler } \\
\text { Ortalaması }\end{array}$ & F & p \\
\hline Gruplar arası & 20,600 & 8 & 2,575 & 3,959 & 0,000 \\
\hline Grup içi & 210,093 & 323 &, 650 & & \\
\hline Toplam & 230,693 & 331 & & & \\
\hline
\end{tabular}

Tablo 13' deki Tek yönlü ANOVA analizi sonuçlarına göre farklı departmanlarda çalışan banka çalışanlarının öznel kariyer başarısına ilişkin algıları arasında anlamlı bir farklılık vardır $\quad(\mathrm{F}(8,323)=3,959 ; \mathrm{p}<0,05)$. Bu sonuçlara göre H6 hipotezi desteklenmektedir. Farklılıkların hangi gruplardan kaynaklandığını gösteren çoklu karşılaştırma Tukey testi sonuçlarına göre ise yöneticilerin (banka müdürü) ve Obi (Orta Büyüklüktek i İşletmeler) departmanı çalışanlarının ̈znel kariyer başarısı algı düzeyleri ile diğer departmanlarda çalışan kişilerin öznel kariyer başarısı algı düzeyleri arasında anlamlı bir farklılık olduğu görülmüştür. Ayrıc a yönetici (banka müdürü) (Ort.= 4,39, S.S. $=0,51$ ) ve obi departmanı çalışanlarının (Ort.= 4,22, S.S.= 0,75) özne 1 kariyer başarısı algı düzeyi ortalamalarının daha yüksek olması sonucu destekler niteliktedir.

Tablo 14. Bankacılık Sektöründeki Çalışanların Bankacılık Sektöründe Çalışma Sürelerine İlişkin Bazı İstatistikler

\begin{tabular}{lccc}
\hline $\begin{array}{l}\text { Çalışanların Bankacılık Sektöründe } \\
\text { Çalışma Süreleri }\end{array}$ & $\mathbf{N}$ & A.Ort & S.S. \\
\hline $\mathbf{1}$ yıldan az & 33 & 3,1212 & 1,03016 \\
\hline $\mathbf{1 - 5}$ yıl & 124 & 3,5806 & 0,69567 \\
\hline $\mathbf{6 - 1 0}$ yıl & 100 & 3,5667 & 0,86131 \\
\hline $\mathbf{1 1 - 1 5}$ yıl & 54 & 3,7531 & 0,84721 \\
\hline $\mathbf{1 6}$ yıl ve üzeri & 21 & 3,7619 & 0,90764 \\
\hline Total & 332 & 3,5703 & 0,83484 \\
\hline
\end{tabular}

Banka çalışanlarının öznel kariyer başarısına ilişkin algılarının sektördeki çalışma sürelerine göre bir farklılık gösterip göstermediği 332 banka çalışanından elde edilen veri üzerinden araştırılmıştır. Örnekleme ilişkin bazı istatistikler ve tek yönlü ANOVA analizi sonuçları Tablo 14 ve Tablo 15'de yer almaktadır. 
Tablo 15. Bankacılık Sektöründe Çalışanların Bankacılık Sektöründeki Çalışma Sürelerine Göre Öznel Kariyer Başarısı Tek Yönlü ANOVA Analizi

\begin{tabular}{lrrrrr}
\hline & $\begin{array}{c}\text { Kareler } \\
\text { Toplamı }\end{array}$ & sd & $\begin{array}{c}\text { Kareler } \\
\text { Ortalaması }\end{array}$ & F & p \\
\hline Gruplar arası & 9,245 & 4 & 2,311 & 3,413 & 0,009 \\
\hline Grup içi & 221,448 & 327 & 0,677 & & \\
\hline Toplam & 230,693 & 331 & & & \\
\hline
\end{tabular}

Tek yönlü ANOVA analizi sonuçlarına göre bankacılık sektöründeki farklı çalışma sürelerine sahip banka çalışanlarının öznel kariyer başarılarına ilişkin görüşleri arasında anlamlı bir farklılık bulunmaktadır ( $\mathrm{F}(4,327)$ $=3,413 ; p<0,05)$. Başka bir ifade ile öznel kariyer başarısı algısı banka çalışanlarının sektördeki çalışma sürelerine göre farklılık göstermektedir. Dolayısı ile H7 hipotezi desteklenmektedir. Farklılıkların hangi gruptan kaynaklandığını bulmak için Tukey testi yapılmış ve farklılıkların 11-15 yıl ile 16 yıl ve üzeri sektörde çalışan bankacılardan kaynaklandığı görülmüştür. Tablo 14 'deki çalışanların sektörde çalışma süreleri kapsamında öznel kariyer başarısı ortalamalarına bakıldığında ortalamaların birbirine yakın olduğu ancak en yüksek ortalamanın 16 yıl ve üzeri (Ort.= 3,76; S.S.= 0,90), 11-15 yıl (Ort.= 3,75; S.S.=0,84) bankacilık sektöründe çalışanlarda olduğu görülmektedir. Bu sonuç yapılan Tukey testini desteklemektedir.

\section{Sonuç, Tartışma ve Öneriler}

Bireylerin çalışma hayatlarındaki başlıca hedeflerinden biri kariyerlerinde başarılı olmaktır. Bu araştırmada kariyer başarısı öznel kariyer başarısı boyutuyla ele alınmıştır. Araştırmada öncelikle öznel kariyer başarısı ile kariyer bağlılı̆̆ı arasındaki ilişki ele alınmıştır. Hem çalışanlar hem de örgütler için önemli olan öznel kariyer başarısını arttıran faktörlerden biri olduğu varsayılan çalışanların kariyer bağlılık düzeylerinin öznel kariyer başarısı algıları üzerinde etkisini tespit etmek amaçlanmıştır. Araştırmanın ilk hipotezi öznel kariyer başarısı ile kariyer bağlılığı öznel kariyer başarısı ve kariyer bağlılı̆̆ı arasındaki pozitif bir nedensellik ilişkisinin varlığı üzerine kurgulanmıştır.

Geliştirilen araştırma hipotezleri Kars'ta faaliyet gösteren banka şubelerinde çalışan 332 personelden alınan verilerin istatistiksel analizler yardımıyla test edilmesi ile bir takım sonuçlara ulaşılmıştır. Araştırmada yapılan analizlerde öncelikle kariyer bağlılığının öznel kariyer başarısı ile olan ilişkisi test edilmiştir. Analiz sonuçları incelendiğinde kariyer bağlılığı ile öznel kariyer başarısı arasında pozitif yönlü, istatistiksel açıdan anlamlı zayıf bir ilişki olduğu görülmüştür. Bu sonuç Ballout (2009), Poon (2004) ve Day ve Allen (2004)'ın yapmış oldukları çalışmalarla benzer bulgulara ulaşıldığını göstermektedir. Buna ek olarak analiz sonuçlarına göre kariyer bağlılı̆̆ının öznel kariyer başarısı üzerinde bir açıklayıcı güce sahip olduğu söylenebilir. Yapılan regresyon analizi sonucunda öznel kariyer başarısındaki \%12'lik bir değişimin kariyer bağlılığı tarafından açıklandığı sonucuna ulaşılmıştır. Alan yazın incelendiğinde araştırmanın bulguları bankacılık sektörü dışında yapılan çalışmaların bulguları ile paralellik göstermektedir. Kariyer bağlılığının sübjektif kariyer başarısı üzerindeki etkisini inceleyen çalışmalarda (Amin, Arshad ve Ghani 2017; Aryee, Chay ve Tan, 1994, , Ballout 2009, Otçuoğlu 2014, Pasha, Hamid ve Shahzad 2017, Corelli ve Bishop 1990, Sultana vd. 2016) kariyerlerine bağlı olan kişilerin kariyerlerinde daha başarılı olma eğiliminde olabilecekleri; bir başka deyişle, öznel kariyer başarısı elde etmek isteyen çalışanlar kariyer kararlarına bağlı olmaları gerektiği sonucuna ulaşılmıştır. Bunun sebebinin belirli bir iş alanında tecrübe edinmenin ve uzmanlaşmanın kişinin öznel kariyer başarısına katkı sağladığı düşünülmektedir.

Diğer yandan banka çalışanlarının algıladıkları öznel kariyer başarılarının demografik değişkenlere göre farklılık gösterdiği varsayılarak araştırmanın diğer hipotezleri kurgulanmıştır. Farklı sektörlerde yapılan çalışmalarda (Eddleston vd., 2004; Greenhaus ve Parasuman 1993; Sturges 1999; Ballout 2009) cinsiyet faktörünün kariyer başarısında önemli bir özellik olduğu tespit edilmiştir. Ayrıca cinsiyet bakımından kariyer başarısı algılarında da farklılık olduğu bahsi geçen çalışmalarda ortaya konmuştur. Bu çalışmada ise öznel kariyer başarısının kadın ve erkek bakımından anlamlı bir farklılığa sahip olduğu ve erkeklerde kadınlardan biraz daha yüksek öznel kariyer başarısı algısının bulunduğu sonucuna ulaşılmıştır. Bu sonuç daha önce yapılan çalışmaların sonuçları ile benzerlik göstermektedir.

Çalışmaya katılan banka çalışanlarının öznel kariyer başarısı algılarının medeni durum bakımından anlamlı bir farklılık göstermediği araştırmanın bir diğer bulgusudur. Ancak bankacılık sektörü dışındaki sektörlerde 
daha önce yapılan çalışmalarda (Chenevert ve Trembley 2002; Ballout 2009; Wayne vd. 1999;) bekâr çalışanların evli çalışanlardan daha yüksek kariyer başarısı algısına sahip oldukları belirlenmiştir. Araştırmanın bu sonucu bankacılık sektöründeki başarı koşullarının evli ya da bekâr çalışanlar için benzer şekilde algılandığı şeklinde değerlendirilmiştir. Katılımcıların yaşlarına göre öznel kariyer başarısı algılarında istatistiksel açıdan anlamlı bir farklılık tespit edilmiştir. Araştırma bulgularına göre çalışanların yaşları arttıkça öznel kariyer başarısı algılarının da arttı̆̆ı görülmektedir. Bu bulgu Eddleston vd. 2004 ve Sturges 1999'un çalışmalarının bulguları ile benzerlik arz etmektedir.

Eğitim düzeyleri açısından bakıldığında araştırmaya katılanların öznel kariyer başarısı algılarında anlamlı bir farklılık bulunamamıştır. Bankaların kurumsal işletmeler oldukları ve hizmet içi eğitimler, kariyer geliştirme programları ile çalışanlarını eğitim bakımından destekledikleri göz önüne alınarak eğitim açısından çalışanlar arasında öznel kariyer başarısı açısından farklılık olmaması açılanabilir. Banka çalışanlarının çalıştıkları departman değişkeni bakımından Obi personeli ve şube yöneticileri en yüksek öznel kariyer başarısı algısına sahiptirler. Son olarak öznel kariyer başarısı sektörde çalışma yılı açısından değerlendirildiğinde en yüksek 15 yıl ve üzeri çalışanlarda hissedilmektedir. Yıl kıdemi arttıkça öznel kariyer başarısı algısı da artmaktadır. Aryee vd., 1994; Judge vd., 1995; Sheridon vd., 1997; Stroh vd., 1992, Tharenou vd., 1994 yapmış oldukları çalışmalarda benzer bulgulara ulaşmışlardır. Bu çalışmaların sonuçlarının mevcut çalışmayı destekler nitelikte olduğu ifade edilebilir.

Araştırma sonucunda elde edilen bulgulara göre; çalışanlarının öznel kariyer başarılarına katkıda bulunmak isteyen işletmelerin liyakate bağlı kalmak ve örgütsel adaleti sağlamak koşuluyla çalışanlarını mutlu olabilecekleri departmana atamaları önerilebilir. Bununla birlikte özellikle kadın çalışanların terfi ve ücret konularında daha adil bir politika izlenmesi öznel kariyer başarısının arttıracaktır. Ancak öznel kariyer başarısı elde etmek isteyen çalışanların işletmedeki pozisyonlarında uzmanlaşmaları ve işe hâkim hale gelmeleri önemlidir. Ayrıca çalışanların sektördeki çalışma süreleri ve yaşları arttıkça kariyer başarılarının da artması bankacılık sektöründe iş güvencesine işaret etmektedir. Bu denklemden hareketle iş güvencesinin öznel kariyer başarısını etkilediği gözlenmektedir.

Bu çalışmada elde edilen bulgular bazı kısıtlar göz önüne alınarak değerlendirilmelidir. Araştırma sadece Kars'ta faaliyet gösteren kamu ve özel banka şubeleri ile sınırlandırılmıştır. Araştırma sonuçları sadece araştırmaya katılan banka çalışanlarının görüşlerini içermektedir. Araştırma zamana ve finansal kaynaklara dayalı kısıtlardan dolayı araştırma sonuçları veri toplama zamanı ve veri toplama alanı ile sınırlıdır. Bu sebeplerden dolayı bu araştırma modeli farklı hizmet sektörlerinde (turizm, sağlık gibi) veya daha büyük bir örneklem hacmi ile Türkiye genelindeki bankalarda yeniden test edilebilir. Diğer yandan araştırmacılara özellikle farklı sektörlerde veya daha büyük bir örneklem hacmi ile bankacılık sektöründe kariyer başarısının belirleyicilerinin incelenmesi önerilmektedir. Bu belirleyicilerin tespit edilmesi ile örgütlerin çalışanlarının verimliliğini yükseltmede bireylerin kariyer başarılarını artıracak politikalar izleyerek sektöre ya da sektörlere faydalı olunacağı düşünülmektedir. 


\section{KAYNAKÇA}

Altunışık, R., Coşkun, R., Bayraktaroğlu, S. ve Yıldırım, E. (2005). Sosyal Bilimlerde Araştırma Yöntemleri SPSS Uygulamalı, Sakarya, Sakarya Kitapevi.

Amin, S., Arshad, R. and Ghani, R. A. (2017). Spousal support and subjective career success: the role ofworkfamily balance and career commitment as mediator, Jurnal Pengurusan 50 (2017), Galley Proof, 1-16.

Arthur, M. B., Khapova, S. N. and Wilderom C. P. M. (2005). Career success in boundaryless career world, Journal of Organizational Behavior, 26(2), 177-202.

Aryee, S., Chay, Y. and Tan, H. H. (1994). An examination of the antecedents of subjective career success among a managerial sample in singopore, Human Relations, 47(5), 487-509.

Ballout, H. I. (2009). Career commitment and career success: moderating role of self-efficacy, Career Development International, 14(7), 655-670.

Biemann, T. ve Braakmann, N. (2013). The impact of international experience on objective and subjective career success in early careers, The International Journal of Human Resource Management, 24(18), 34383456.

Blau, G. (1985). The measurement and predict on of career commitment, Journal of Occupational Psychology, $58,277-288$.

Boudreau, J. W., Boswell, W. R., Judge, T. A. (2001). Effects of Personality on Executive Career Success in the United States and Europe", Journal of Vocational Behavior, 58(1), 53-81.

Carmelli, A. ve Gefen, D., (2005). “The Relationship Between Work Commitment Models and Employee Withdrawal Intentions", Journal of Managerial Psychology, 20(2), 1-49.

Chenevert, D. ve Tremblay, M. (2002) "Managerial Career Success in Canadian Organizations: Is Gender a Determinant?", International Journal of Human Resource Management, 13(6): 920-941.

Chung Y. B., (2002). “Career Decision-Making Self-Effiacy and Career Commitment: Gender and Ethnic Differences Among Collage Students", Journal of Career Development, 28 (4), 277-284.

Cohen, A., (2003). Multiple Commitments in The Work-Place: An Integrative Approach, Lawrence Erlbaum Associates Publishers, Mahwah NJ.

Cohen, J., (1988). Statistical Power Analysis For The Behavioral Sciences, Michigan, NJ: Lawrence Erlbaum

Corelli, S. M. ve Bishop, R. C., (1990). Career Commitment: Functions, Correlates and Management. Group and Organization Studies,15(2), 158-178.

Day, R. ve Allen, T., (2004). The Relationship Between Career Motivation and Self-Efficacy with Protégé Career Success. Journal of Vocational Behavior, 64, 72-91.

Eddleston K. A., Baldridge D. C., Veiga J. F., (2004). “Toward Modeling The Predictors of Managerial Career Success: Does Gender Matter?", Journal of Managerial Psychology, 19(4), 360-385.

Greenhaus J. ve Parasuman A., (1993). Job Performance Attributions and Career Advancement Prospects: An Examination of Gender and Race Effects, Organizational Behavior and Human Decision Processes, 55(2), 273-297.

Gökmen, S., (1996). İşletmeye Bağlılık Anketini Türkçe 'ye Uyarlama ve Geçerlilik ve Güvenilirlik Katsayılarını Belirleme Çalışması, Yayımlanmamış Yüksek Lisans Tezi, Ankara Hacettepe Üniversitesi, Sosyal Bilimler Enstitüsü. Ankara.

Gürbüz, S. ve Şahin, F., (2017). Sosyal Bilimlerde Araştırma Yöntemleri, Ankara, Seçkin Yayıncllık.

Hennekam, S., (1996). "Vitality of Older Workers and Its Relationship with Performance: Career Satisfaction and Career Suceess", Revue Management\&Avenir, 83, 15-32. 
Heslin, P. A. (2005). Conceptualizing and Evaluating Career Success, Journal of Organizational Behavior, 26(2), 113-136.

Judge, T. A., Cable, D. M., Boudreau, J. W. ve Bretzjr, R. D. B., (1995). “An Empirical Investigation of The Predictor of Executive Career Success", Personnel Psychology, 48, 485-519.

Kalaycı, Ş., (2010). SPSS Uygulamalı Çok Değişkenli İstatistik Teknikleri, Asil Yayıncılık, Ankara.

Karasar, N., (2012). Bilimsel Araştırma Yöntemi, Nobel Yayın Dağıtım, Ankara.

Karavardar, G., (2014). "Career Commitment, Subjective Career Success and Career Satisfaction in The Context of Hazelnut Processing Industry in Giresun/Turkey", International Journal of Business and Management, 9(6), 98-105.

Nakip, M., (2013). SPSS Uygulamalı Pazarlamada Araştırma Teknikleri, Seçkin Yayıncılık, Ankara.

Ng, T. W., Eby,l. T., Sorensen, K. L. ve Feldman,D. C. (2005) "Predictors of Objective and Subjective Career Success: A Meta-Analysis", Personnel Psychology, 58(2): 367-408.

Otçuoğlu, Ö. Ç., (2014). “Kariyer Bağlılığının Kariyer Başarısı Üzerine Etkisinin İncelenmesi Üzerine Bir Araştırma", Yönetim ve Ekonomi Araştırmaları Dergisi, Sayı:23: 350-363.

Özdamar, K., (2002). Paket Programlar ile İstatistiksel Veri Analizi (4. Baskı), Kaan Yayınları, Eskişehir.

Pasha, A. T., Hamid, K. A., Shahzad, A., (2017). "Mediating Role of Career Commitment in the Relationship of Promotional Opportunities, Rewards and Career Success", Pakistan Journal of Statistics \& Operation Research, 13 (1), 185-199.

Poon, J. M. L., (2004). "Career Commitment and Career Success: Moderating Role of Emotion Perception", Career Development International, 9(4), 374-390.

Rashid, H., Zhao, L., (2010). "The Significance of Career Commitment in Genarating Commitment to Organizational Change Among Information Technology Personnel", Academy of Information and Management, 13(1), 111-131.

Sheridan, J. E., Slocum, J. W. and Buda, R. (1997). `Factors infuencing the probability of employee promotions: a comparative analysis of human capital, organization screening and gender/race discrimination theories', Journal of Business and Psychology, 11, 373-380.

Stroh, L. K., Brett, J. M. and Reilly, A. H. (1992). 'All the right stu€: a comparison of female and male managers' career progression', Journal of Applied Psychology, 77, 251-260.

Sturges, J., (1999). “What It Means to Succeed: Personal Conceptions of Career Success Held by Male and Female Managers at Different Ages", British Journal of Management, 10 (3), 239-252.

Sultana, R., Yousaf, A., Khan, I., Saeed, A, (2016). "Probing The Interactive Effects of Career Commitment and Emotional Intelligence on Percieved Objective/Subjective Career Success", Personnel Review, Vol: 45, No:4, 724-742.

Sutin, A. R., Costa, P. T., Miech, R., Eaton, W. W., (2009). “Personality and Career Success: A Concurrent and Longitudinal Relations", Europen Journal of Personality, 23 (2), 71-84.

Tharenou, P., Latimer, S. and Conroy, D. (1994). 'How do you make it to the top? A examination of infuences on women's and men's managerial advancement', Academy of Management Journal, 37, 899-931.

Turban, D. B., Dougherty, T. W., (1994). “Role of Protégé Personality in Receipt of Mentoring and Career Success", Academy of Management Journal, 37(3), 688-702. 
Wayne, S. J., Liden, R. C., Kraimer, M. L., Graf, I. K., (1999). “The Role of Human Capital Motivation and Supervisor Sponsorship in Predicting Career Success", Journal of Organizational Behavior, 20(5), 577-595.

Yan, Y. W., (2005). Antecedents and Outcomes of Employees Participation in Development Activity, An Honours Degree Project, Hong Kong Baptist University 1-45.

Yang, Y., (2011). "Gender and Engineering CareerDevelopment of Hotel's Employees in China", Systems Engineering Procedia, 1, 365-371.

Yean, T. F., Yahya, K. K., (2013). "The Influence of Human Resource Management Practices and Career Strategy on Career Satisfaction of Insurance Agents", Vol: 14, No: 2, 193-206.

Yu, C., (2012) "Career Success and Its Predictors: Comparing Between Canadian and Chinese", International Journal of Business Management, 7(14), 88-95. 